\title{
Assessment of Knowledge on Risk Factors, Warning Signs, and Early Treatment Approaches of Stroke among Community Adults in North India: A Telephone Interview Survey
}

\author{
Hashim Khan ${ }^{5}$
${ }^{1}$ Department of Pharmacy Practice, Indo-Soviet Friendship College of Pharmacy, Moga, Punjab, India
${ }^{2}$ College of Pharmacy, Rady Faculty of Health Sciences, University of Manitoba, Manitoba, Canada
${ }^{3}$ Department of Pharmacy Practice, Sri Adichunchanagiri College of
Pharmacy, Adichunchanagiri University, Mandya, Karnataka, India
${ }^{4}$ Department of Pharmacy Practice, Adesh Institute of
Pharmaceutical and Biomedical Sciences, Bathinda, Punjab, India
${ }^{5}$ Department of Pharmacy Practice, College of Pharmacy,
Teerthanker Mahaveer University (TMU), Moradabad,
Uttar Pradesh, India

J Neurosci Rural Pract 2019;10:417-422

\begin{abstract}
Address for correspondence Sai Krishna Gudi, MSc, Department of Pharmacy, Rady Faculty of Health Sciences, University of Manitoba, Manitoba, Canada (e-mail: sknanu06@gmail.com).
\end{abstract}

\begin{abstract}
Background As stroke is a catastrophic illness, knowing its risk factors, early signs and symptoms, and management strategies could potentially prevent morbidity and mortality among the people.

Objectives The aim of this study is to determine the public cognizance of risk factors, signs and symptoms, and early treatment options available for stroke with particular emphases on thrombolysis, and its window period.

Materials and Methods A cross-sectional telephonic interview-based survey was conducted in the states of Punjab, Haryana, and Himachal Pradesh of North India from August 2017 to December 2017.

Results Of 350 respondents those participated in the survey with a mean age \pm standard deviation of $39.93 \pm 13.41$ years, hypertension was found to be the most common risk factor among the study participants $(n=205,58.57 \%)$ and $28.85 \%$ of the study participants were not aware of the risk factors, whereas $46 \%$ of the participants were not aware of warning signs of stroke. The window period of thrombolysis was

Keywords

- community adults

- risk factors

- stroke

- telephone interview survey

- warning signs compared with gender, and it was found that the higher number of male participants ( $n=49$ ) adduced the right window of thrombolysis (0-4.5 hours) as compared with the female participants $(n=26)$.

Conclusions Survey results suggested that there exists scant information about risk factors, alarming signs, and early treatment approaches among community adults toward stroke. In this regard, there is an immense need to conduct awareness camps related to stroke to educate the vulnerable public.
\end{abstract}

DOI https://doi.org/

10.1055/s-0039-1697561

ISSN 0976-3147.
C2019 Association for Helping

Neurosurgical Sick People
License terms

()(1) $\Theta \circledast$ 


\section{Introduction}

According to the World Health Organization, stroke is a clinical syndrome of rapidly developing signs of focal disturbance of cerebral function, which lasts $>24$ hours or may even lead to death, without possible cause other than the vascular origin. ${ }^{1}$ Stroke can be prevented by controlling its risk factors such as diabetes, hypertension, smoking, alcohol use, and drug abuse.,3 Recent evidence suggesting the initiation of early thrombolysis in patients with stroke has added the benchmark in its management strategies. ${ }^{4}$ Despite the advanced progression in the therapeutic management of stroke, the burden of the disease is rising day by day as stroke patients fail to seek instant medical attention which results in the poor therapeutic outcomes. ${ }^{5}$ Numerous studies have reported that stroke patients get delayed in hospitalization due to the lack of awareness regarding the early recognition of signs and symptoms of the stroke.-9 As various studies stated that the patients who receive early thrombolysis gets better therapeutic outcome; however, it depends on the time duration of the arrival of a patient to the hospital to seek medical care from the time of the onset of the symptoms. ${ }^{10}$ Since the window period to be eligible for thrombolysis is less, patients must report within 4.5 hours from the onset of the symptoms to get eligible for thrombolysis. ${ }^{11}$ However, $90 \%$ of the patients fail to be eligible for thrombolysis due to inadequate knowledge regarding the stroke symptoms and early treatment options available. ${ }^{12}$ Hence, to assess the community adults' knowledge regarding stroke, a cross-sectional survey was conducted in Punjab, Haryana, and Himachal Pradesh of North India.

\section{Aim of the Study}

The primary objective of this survey is to assess the knowledge of community adults living in three primary states, that is, Punjab, Haryana, and Himachal Pradesh, of northwest India with regard to risk factors, signs and symptoms, and early treatment strategies, especially thrombolytic therapy.

\section{Materials and Methods}

A cross-sectional telephonic survey was conducted from August 2017 to December 2017 in three primary states, that is, Punjab, Haryana, and Himachal Pradesh, of North India. The study was commenced after getting approval from the institutional ethics committee, and verbal informed consent was obtained from each study participant before initiating the survey. The questionnaire was prepared after reviewing similar published studies conducted in India, and it was modified accordingly to suite for a telephonic interview based on the feedback received from the faculties of medical and pharmaceuticals sciences. Items in the questionnaire which were $<80 \%$ of content validity index were deleted. A telephonic interview survey was employed to conduct the survey, which used a random-digit-dial method, and quota sampling was used for the selection of participants from the three states of Punjab, Haryana, and Himachal Pradesh. Participants aged $\geq 18$ years were included in the study, and participants who suffered from stroke were excluded from the study. A telephonic interview was conducted for the eligible participants with a well-framed, open-ended questionnaire to access the knowledge of risk factors, signs and symptoms, and treatment options of stroke. Early-phase questionnaire consisted of demographic details such as marital status, occupation, and socioeconomic class; and the modified Kuppuswamy scale was used to categorize the participants according to their socioeconomic class. Considering the consumer price index during the time of the interview, participants with a score range of 26 to 29,16 to 25 , 11 to 15,5 to 10 , and $<5$ of the modified Kuppuswamy scale were categorized as under upper class, upper middle, upper lower, and lower class, respectively. The questionnaire also consists of information such as chronic diseases with which the study participant is suffering from, risk factors, signs and symptoms, first response/action whenever they see patient with signs of stroke, blood pressure, family history of stroke, knowledge of thrombolysis, window period of thrombolysis, and the source of their knowledge regarding stroke.

\section{Statistical Analysis}

The statistical analysis was performed using IBM SPSS Statistics for Windows, Version 20.0. (Armonk, NY: IBM Corp).. ${ }^{13}$ Univariate analysis was conducted using the chi-square test, and descriptive data were presented in the form of mean \pm standard deviation. Variables included in the analysis were gender, marital status, state of residence, sector of job, and socioeconomic class as per the modified Kuppuswamy scale, and a $p$-value of $<0.05$ was considered statistically significant.

\section{Results}

Of a total of 500 participants approached, 350 participants responded to the survey and qualified the inclusion criteria. Of 350 participants who were included in the study, the male-to-female ratio was found to be $1: 2.2$, and the mean age was found to be $39.93 \pm 13.41$ years. Among the survey participants, 260 (74.3\%) were married and 85 (24.3\%) were unmarried. Almost equal number of survey participants were included from the participating states, that is, Haryana (115), Punjab (109), and Himachal Pradesh (126), respectively. Among the survey participants, most of the participants were working in the private sector ( $n=187,53.4 \%$ ), and 127 (36.3\%) participants belonged to the upper middle socioeconomic status. Other demographic variables are summarized in - Table $\mathbf{1}$.

\section{Knowledge of Survey Participants toward Risk Factors of Stroke}

Of 350 participants, 101 (28.85\%) study participants were not aware of stroke risk factors. From the study results, hypertension was found to be the most common risk factor among the respondents ( $n=205,58.57 \%$ ), followed by poor eating ( $n=153,43.71 \%)$, hyperlipidemia $(n=94,26.85 \%)$, smoking ( $n=78,22.28 \%)$, alcohol use ( $n=49,14 \%)$, and tobacco consumption ( $n=46,13.14 \%)$; interestingly, diabetes was the 
Table 1 Categorization of survey participants based on their sociodemographic profile

\begin{tabular}{|c|c|}
\hline Variables & Frequency (\%) \\
\hline \multicolumn{2}{|l|}{ Age } \\
\hline$<50$ & $269(76.85)$ \\
\hline$\geq 50$ & $81(23.15)$ \\
\hline \multicolumn{2}{|l|}{ Gender } \\
\hline Female & $107(30.6)$ \\
\hline Male & $243(69.4)$ \\
\hline \multicolumn{2}{|l|}{ Marital status } \\
\hline Divorce & $2(0.6)$ \\
\hline Married & $85(24.3)$ \\
\hline Unmarried & $260(74.3)$ \\
\hline Widow & $3(0.9)$ \\
\hline \multicolumn{2}{|l|}{ State } \\
\hline Haryana & 115 (32.9) \\
\hline Himachal Pradesh & $109(31.1)$ \\
\hline Punjab & $126(36.0)$ \\
\hline \multicolumn{2}{|l|}{ Job sector } \\
\hline Government & $41(11.7)$ \\
\hline Private & $187(53.4)$ \\
\hline Semigovernment & $8(2.3)$ \\
\hline Unemployed & $114(32.6)$ \\
\hline \multicolumn{2}{|c|}{ Socioeconomic status (as per Kuppuswamy scale) } \\
\hline Upper (26-29) & $74(21.1)$ \\
\hline Upper middle (16-25) & $127(36.3)$ \\
\hline Lower middle (11-15) & $95(27.1)$ \\
\hline Upper lower (5-10) & $23(6.6)$ \\
\hline Lower $(<5)$ & $31(8.9)$ \\
\hline
\end{tabular}

least recognized risk factor ( $n=16,4.57 \%$ ) among the participants. The survey participants' knowledge of risk factors is detailed in - Table 2.

\section{Knowledge of Survey Participants toward the Warning Signs of Stroke}

Unfortunately, almost half of the survey participants were not aware of the warning signs of stroke ( $n=161,46 \%)$, and difficulty in speaking and understanding or slurred speech was the second-most common warning signs recognized by the participants ( $n=80,22.9 \%$ ). While a severe headache with unknown cause ( $n=4,1.1 \%$ ) was the least recognized warning sign; all other warning signs recognized by the participants are detailed in - Table 2.

Initial Responses of Survey Participants on Recognizing Patient Suffering from a Stroke

Survey results have stated that the higher number of participants will themselves take the patient to the hospital immediately ( $n=107,30.6)$ with a $\chi^{2}=183.8$ and a statistically significant $p$-value of $<0.001$, followed by "call to the ambulance-108 services" ( $n=121,34.6 \%)$. Furthermore,
Table 2 Knowledge of risk factors and warning signs among survey participants toward stroke

\begin{tabular}{|c|c|}
\hline Variables & Frequency (\%) \\
\hline \multicolumn{2}{|l|}{ Risk factors } \\
\hline Diabetes $^{\mathrm{a}}$ & $16(4.57)$ \\
\hline Hypertension ${ }^{\mathrm{a}}$ & $205(58.57)$ \\
\hline Hyperlipidemia ${ }^{a}$ & $94(26.85)$ \\
\hline Alcohol $^{\mathrm{a}}$ & $49(14)$ \\
\hline Tobacco & $46(13.14)$ \\
\hline Smoking ${ }^{a}$ & $78(22.28)$ \\
\hline Poor eating & $153(43.71)$ \\
\hline No knowledge of risk factors & $101(28.85)$ \\
\hline \multicolumn{2}{|l|}{ Warning signs } \\
\hline Blurred vision in 1 or both eyes ${ }^{\mathrm{a}}$ & $11(3.2)$ \\
\hline Chest pain or heart palpitations & $23(6.6)$ \\
\hline $\begin{array}{l}\text { Difficulty in speaking and un- } \\
\text { derstanding or slurred speech }\end{array}$ & 80 (22.9) \\
\hline Difficulty in walking ${ }^{a}$ & $8(2.3)$ \\
\hline Dizziness & $6(1.7)$ \\
\hline Do not know & $161(46)$ \\
\hline Loss of balance & $15(4.3)$ \\
\hline $\begin{array}{l}\text { Numbness or weakness of the } \\
\text { face and/or limbs of the body }\end{array}$ & $20(5.7)$ \\
\hline $\begin{array}{l}\text { Severe headache with unknown } \\
\text { cause }\end{array}$ & $4(1.1)$ \\
\hline Shortness of breath & $22(6.3)$ \\
\hline
\end{tabular}

aRisk factor and warning signs of stroke which are established.

least number of participants $(n=16,4.6 \%)$ reported that they would not do anything, let the patient recover himself/ herself. All other initial responses are detailed in - Table 3.

\section{The Source of Information among Survey Participants toward Stroke Education}

Among the survey participants, a higher number of respondents had stated that the pharmacist as their primary source of information on stroke education ( $n=117,33.4 \%$ ), whereas physicians as the secondary source of their education on stroke ( $n=107,30.6 \%)$. These values were found to be statistically significant with a $\chi^{2}=123.83$ at $p$-value of $<0.001$ when compared with the participants who did not respond correctly. The rest of the other values are detailed in - Table 3 .

\section{Knowledge among Survey Participants toward a Window Period of Thrombolysis}

The window period of thrombolysis was compared with gender, and it was found that the higher number of male participants $(n=49)$ adduced the right window period of thrombolysis (i.e., $0-4.5$ hours) as compared with the female participants $(n=26)$. However, these values were not found to be statistically significant with a $\chi^{2}=5.193$ at a $p$-value of 0.268 , when compared with the participants who did not respond correctly. On comparison of the socioeconomic 
Table 3 Survey participants' early responses and source of information toward stroke

\begin{tabular}{|c|c|c|}
\hline Questions & $\begin{array}{l}\text { Frequency } \\
\text { (\%) }\end{array}$ & $\chi^{2}, p$-Value \\
\hline \multicolumn{3}{|l|}{$\begin{array}{l}\text { What will be your quick response } \\
\text { if you see any of your member } \\
\text { getting attack of stroke? }\end{array}$} \\
\hline I will call to ambulance (108) & $121(34.6)$ & \multirow{5}{*}{$\begin{array}{l}183.8 \\
<0.001\end{array}$} \\
\hline I will give home remedies & $20(5.7)$ & \\
\hline I will give patient first morphine & $55(15.7)$ & \\
\hline $\begin{array}{l}\text { I won't do anything, let the } \\
\text { patient recover himself/herself }\end{array}$ & $16(4.6)$ & \\
\hline $\begin{array}{l}\text { I myself will take patient to } \\
\text { hospital immediately }\end{array}$ & $138(39.4)$ & \\
\hline \multicolumn{3}{|l|}{$\begin{array}{l}\text { Source of information on stroke } \\
\text { education }\end{array}$} \\
\hline Physicians & $107(30.6)$ & \multirow{5}{*}{$\begin{array}{l}123.83 \\
<0.001\end{array}$} \\
\hline Newspaper/magazines & $49(14)$ & \\
\hline Nurses & $2(0.6)$ & \\
\hline Pharmacist & $117(33.4)$ & \\
\hline Relatives/friends & $75(21.4)$ & \\
\hline
\end{tabular}

class with the window period of thrombolysis, it was found that the higher number of participants from the upper middle class (35) marked the correct option followed by the lower middle class (20), and the lower class reported the least response with a $\chi^{2}=23.991$ at a $p$-value of 0.090 . On comparison of organization of work with the window period of thrombolysis, it was found that a higher number of participants who marked the correct option were from the private sector, and the least were from the semigovernment sector. The obtained results were found to be statistically significant with a $\chi^{2}=66.361$ at a $p$-value of $<0.001$ when compared with the participants who did not respond correctly. When the responses of these three states were compared, it was noticed that an equal number of participants from Haryana and Punjab marked the correct window period of thrombolysis. All other values of comparison of the window period of thrombolysis are described in - Table 4 .

\section{Discussion}

Stroke is an alarming issue in developing countries as compared with the developed countries, ${ }^{14}$ and it is considered as the primary cause of morbidity and mortality among noncommunicable diseases. ${ }^{15}$ Stroke can be prevented and treated if its risk factors are modified and if warning signs are recognized earlier. ${ }^{16}$ In recent times, thrombolysis has added as a cornerstone in the history of treatment of stroke, ${ }^{17}$ and it is believed that there is a maximum chance of recovery with early initiation of thrombolysis among ischemic stroke patients. ${ }^{16}$ Astonishingly, many studies in the past had reported that patients suffering from a stroke fail to arrive at the hospital within the window period of thrombolysis due to the lack of recognition of stroke symptoms, and they were not aware of the actions to react if anyone is suffering from a stroke. ${ }^{18}$ Moreover, patients are not aware of early thrombolysis, which can eventually save the life of patients by improving morbidity and mortality associated with stroke.

Table 4 Comparison of knowledge on thrombolysis with demographic variables among survey participants

\begin{tabular}{|c|c|c|c|c|c|}
\hline \multirow[t]{2}{*}{ Variables } & \multicolumn{4}{|c|}{ Window period of thrombolysis } & \multirow[t]{2}{*}{$\chi^{2}, p$-Value } \\
\hline & $0-4.5 \mathrm{~h}$ & $4.5-6 \mathrm{~h}$ & $12-24 \mathrm{~h}$ & $>24 \mathrm{~h}$ & \\
\hline \multicolumn{6}{|l|}{ Gender } \\
\hline Male & 49 & 25 & 13 & 2 & \multirow{2}{*}{$5.193,0.268$} \\
\hline Female & 26 & 5 & 3 & 2 & \\
\hline \multicolumn{6}{|l|}{ Socioeconomic classes } \\
\hline Upper & 15 & 4 & 3 & 1 & \multirow{5}{*}{$23.991,0.090$} \\
\hline Upper middle & 35 & 12 & 4 & 1 & \\
\hline Lower middle & 20 & 9 & 4 & 1 & \\
\hline Upper lower & 4 & 1 & 0 & 1 & \\
\hline Lower & 1 & 4 & 5 & 0 & \\
\hline \multicolumn{6}{|l|}{ Organization of work } \\
\hline Government & 6 & 2 & 9 & 22 & \multirow{4}{*}{$66.361,<0.0001$} \\
\hline Semigovernment & 0 & 4 & 0 & 4 & \\
\hline Private & 49 & 19 & 5 & 122 & \\
\hline Unemployed & 20 & 5 & 2 & 87 & \\
\hline \multicolumn{6}{|l|}{ States } \\
\hline Haryana & 2 & 5 & 29 & 10 & \multirow{3}{*}{$5.463,0.707$} \\
\hline Himachal Pradesh & 0 & 6 & 25 & 10 & \\
\hline Punjab & 2 & 5 & 21 & 10 & \\
\hline
\end{tabular}


This survey results have proven that there exists a poor awareness regarding stroke among the public of three states of North India. There is a need for organizing health awareness camps on stroke risk factors and their management. Educating the public on signs and symptoms of stroke would make patients receive early medical care by attaining the window period of thrombolysis. Remarkably, very few people were aware of the risk factors of stroke, and only 4.57, 58.57, and $22.28 \%$ of people recognized diabetes, hypertension, and smoking as a risk factor causing stroke, respectively. The results of this study were in accordance with a South Indian study conducted by Menon et al in 2014, as they observed that $50 \%$ of the participants marked hypertension as a risk factor, whereas $40 \%$ of the participants marked diabetes as a risk factor, and $39 \%$ of participants marked alcohol as a risk factor of stroke, respectively..$^{18}$ From this, it infers that there is no notable difference with regard to the knowledge on risk factors of stroke between South and North Indian states, which suggests that there is an immense need to create awareness to prevent stroke in India. In a similar study conducted by Pandian et al in 2006, concluded that 54 and 31\% of their study participants had identified hypertension and diabetes as the most common risk factors causing a stroke. ${ }^{12}$

Nearly about half of the study participants (46\%) were not aware of the warning signs of a stroke, whereas $22.9 \%$ of the participants marked "difficulty in speaking and understanding or slurred speech" as a warning sign. Surprisingly, only $5.7 \%$ of the participants marked "numbness or weakness of the face and/or limbs of the body" as an early warning sign which depicted poor awareness of warning signs of stroke among the North Indian public. These findings were in contrast with the similar study conducted by Pandian et al in 2006, where the study findings infer that $62 \%$ of their participants had reported paralysis as the leading warning symptom of stroke. ${ }^{12}$ On comparing the knowledge of warning signs with the similar study conducted by Donkor et al in 2014, it was found that people of Ghana were more aware of the warning signs and only $22 \%$ of their participants were not aware of the warning sign of stroke. ${ }^{10}$ In addition to inadequate knowledge of risk factor, only $34.6 \%$ of the participants answered the right approach, that is, they would call ambulance-108 service on recognizing the patient getting stroke attack, whereas $15.7 \%$ responded that they would give morphine first to the patient. From our study results, we observed that pharmacists are the primary source of the community's information on stroke followed by physicians and nurses, respectively, because of higher patient-to-pharmacist ratio in India. Early thrombolysis plays a crucial role in determining the mortality and disability in stroke survivals, but unfortunately, this study results stated that most of the people were not aware of thrombolysis, and people who were aware, they did not know the actual window period of thrombolysis.

As per the best of our knowledge, this is a very first study of its kind, which addressed the community's awareness of thrombolysis and its window period. The number of males recognized the accurate time of thrombolysis with regard to socioeconomic class, and people from higher socioeconomic class were aware of an actual window period of thrombolysis; which indicates that there is an immense need to create more awareness among people who belong to lower socioeconomic classes. On comparison of the window period of thrombolysis with organization of work, we found that people working in the private sector marked the correct window period. Interestingly, we also found that not even a single subject from Himachal Pradesh marked the actual window period of thrombolysis, which indicates the lack of awareness of thrombolysis among the people of Himachal Pradesh.

\section{Conclusion}

From the survey results, we conclude that there exists a poor awareness among the general community adults of Punjab, Haryana, and Himachal Pradesh toward risk factors, warning signs, and early treatment approaches in stroke patients. As this is a serious concern and proves to be a significant cause of increased mortality and morbidity due to stroke, there is a need to initiate stroke awareness camps to make the community aware which can eventually prevent disability and increase the chances of recovery among stroke patients.

\section{Limitations}

The sample size and duration of the study are restricted to 350 respondents and 5 months in time; thus, the scope and extent of the conducted research might be minimized.

This survey was conducted only in three states of North India, and hence, these findings cannot be generalized all over India.

\section{Funding}

None.

\section{Conflict of Interest}

None declared.

\section{References}

1 Developed by the National Collaborating Centre for Chronic Conditions, Stroke: A National Clinical Guideline for Diagnosis and Initial Management of Acute Stroke and Transient Ischaemic Attack (TIA)? London: Royal College of Physicians; 2008

2 El-Hajj M, Salameh P, Rachidi S, Al-Hajje A, Hosseini H. Development of a diagnosis score for stroke in the Lebanese population. Clin Epidemiol Glob Health 2018;7:79-87

3 Boehme AK, Esenwa C, Elkind MS. Stroke risk factors, genetics, and prevention. Circ Res 2017;120(3):472-495

4 Tsivgoulis G, Katsanos AH, Mavridis D, et al. Intravenous thrombolysis for ischemic stroke patients on dual antiplatelets. Ann Neurol 2018;84(1):89-97

5 Faiz KW, Sundseth A, Thommessen B, Rønning OM. Patient knowledge on stroke risk factors, symptoms and treatment options. Vasc Health Risk Manag 2018;14:37-40

6 Rowe AK, Frankel MR, Sanders KA. Stroke awareness among Georgia adults: epidemiology and considerations regarding measurement. South Med J 2001;94(6):613-618

7 Nansseu JR, Atangana CP, Petnga SN, Kamtchum-Tatuene J, Noubiap JJ. Assessment of the general public's knowledge of stroke: a cross-sectional study in Yaoundé, Cameroon. J Neurol Sci 2017;378:123-129

8 Pandian JD, Srikanth V, Read SJ, Thrift AG. Poverty and stroke in India: a time to act. Stroke 2007;38(11):3063-3069 
9 Stroebele N, Müller-Riemenschneider F, Nolte CH. MüllerNordhorn J, Bockelbrink A, Willich SN. Knowledge of risk factors, and warning signs of stroke: a systematic review from a gender perspective. Int J. Stroke 2011;6(1):60-66

10 Donkor ES, Owolabi MO, Bampoh P, Aspelund T, Gudnason V. Community awareness of stroke in Accra, Ghana. BMC Public Health 2014;14:196

11 Lyden PD, Thrombolytic Therapy for Stroke. Switzerland: Springer; 2001

12 Pandian JD, Kalra G, Jaison A, et al. Knowledge of stroke among stroke patients and their relatives in Northwest India. Neurol India 2006;54(2):152-156, discussion156

13 SPSS, IBM SPSS Statistics Base 20. Chicago, IL: SPSS Inc; 2011

14 Das S, Das SK. Knowledge, attitude and practice of stroke in India versus other developed and developing countries. Ann Indian Acad Neurol 2013;16(4):488-493

15 Ingall T. Stroke-incidence, mortality, morbidity and risk. J Insur Med 2004;36(2):143-152

16 Adams HP. del Zoppo G, Alberts MJ, Jr American Heart Association/American Stroke Association Stroke Council, et al. American Heart Association/American Stroke Association Clinical Cardiology Council American Heart Association/American Stroke Association Cardiovascular Radiology and Intervention
Council Atherosclerotic Peripheral Vascular Disease Working Group Quality of Care Outcomes in Research Interdisciplinary Working Group. Guidelines for the early management of adults with ischemic stroke: a guideline from the American Heart Association/American Stroke Association Stroke Council, Clinical Cardiology Council, Cardiovascular Radiology and Intervention Council, and the Atherosclerotic Peripheral Vascular Disease and Quality of Care Outcomes in Research Interdisciplinary Working Groups: The American Academy of Neurology affirms the value of this guideline as an educational tool for neurologists. Circulation 2007;115(20):e478-e534

17 Jauch EC, Saver JL, Adams HP, Jr American Heart Association Stroke Council, et al. Council on Cardiovascular Nursing Council on Peripheral Vascular Disease Council on Clinical Cardiology. Guidelines for the early management of patients with acute ischemic stroke: a guideline for healthcare professionals from the American Heart Association/American Stroke Association. Stroke 2013;44(3):870-947

18 Menon B, Swaroop JJ, Deepika HKR, Conjeevaram J, Munisusmitha K. Poor awareness of stroke-a hospital-based study from South India: an urgent need for awareness programs. J Stroke Cerebrovasc Dis 2014;23(8):2091-2098 